\title{
TRILOGI DIMENSI FILSAFAT DALAM PENGEMBANGAN PENDIDIKAN ISLAM
}

\author{
Tabrani. ZA \\ Universitas Serambi Mekkah, Indonesia \\ Contributor Email: tabraniza@serambimekkah.ac.id
}

\begin{abstract}
Abstrak
Pendidikan menyandang misi keseluruhan aspek kebutuhan hidup dan berproses sejalan dengan dinamika hidup serta perubahan-perubahan yang terjadi. Sebagai akibat logisnya maka pendidikan senantiasa mengandung pemikiran dan kajian, baik secara konseptual maupun secara operasional, sehingga diperoleh relevan dan kemampuan menjawab tantangan serta memecahkan masalah-masalah yang dihadapi oleh umat manusia. Filsafat pendidikan Islam pada hakikatnya adalah konsep berpikir tentang kependidikan yang bersumber atau berlandaskan atas ajaran-ajaran agama Islam. Filsafat pendidikan Islam adalah pembahasan tentang hakikat kemampuan Muslim untuk dapat dibina, dikembangkan, dan dibimbing, sehingga menjadi manusia yang seluruh pribadinya dijiwai oleh ajaran Islam. Filsafat mengajukan pertanyaan dan menyelidiki realita dan pengalaman yang banyak terdapat dalam pendidikan. Filsafat dan pendidikan mempunyai hubungan yang erat satu sama lain, karena problema-problema tersebut berada dalam lingkungan dua disiplin ini. Pendidikan dalam pengembangan konsep-konsepnya antara lain menggunakan dasardasar dari kedua konsep tersebut yaitu filsafat dan pendidikan.
\end{abstract}

Kata Kunci: Filsafat, Islam, Pendidikan, Epistemologi

\section{A. Pendahuluan}

Ajaran Islam menetapkan bahwa pendidikan merupakan salah satu kegiatan yang wajib hukumnya bagi pria dan wanita, dan berlangsung seumur hidup sejak dari buaian hingga ke liang lahat. Kedudukan hukum tersebut secara tidak langsung telah menempatkan pendidikan sebagai bagian yang tak terpisahkan dengan hidup dan kehidupan umat manusia, dalam hal ini hubungannya antara manusia dengan Tuhannya, hubungannya antara manusia dengan alam, dan hubungannya antara manusia dengan manusia lain. 
Pendidikan sebagai salah satu kebutuhan hidup manusia baik masyarakat maupun individu, sebagai salah satu sosial, sebagai bimbingan, sebagai sarana pertumbuhan, yang mempersiapkan dan membukakan serta membentuk disiplin hidup, lewat transmisi baik dalam bentuk informal, formal maupun nonformal. Kalau melihat perkembangan pendidikan di zaman modern ini dengan proses hidup dan kehidupan manusia, keduanya berjalan seiring bersama-sama antara satu dengan yang lainnya tidak terpisah.

Dengan demikian pendidikan menyandang misi keseluruhan aspek kebutuhan hidup dan berproses sejalan dengan dinamika hidup serta perubahan-perubahan yang terjadi. Sebagai akibat logisnya maka pendidikan senantiasa mengandung pemikiran dan kajian, baik secara konseptual maupun secara operasional, sehingga diperoleh relevan dan kemampuan menjawab tantangan serta memecahkan masalah-masalah yang dihadapi oleh umat manusia.

Pemikiran dan kajian tentang pendidikan dilakukan oleh para ahli dalam berbagai sudut tinjauan dan disiplin ilmu, seperti agama, Filsafat, sosiologi, ekonomi, politik, sejarah dan antropologi. Sudut tinjauan ini menyebabkan lahirnya cabang ilmu pengetahuan kependidikan yang berpangkal dari sudut tinjauannya, yaitu pendidikan agama, filsafat pendidikan, sosiologi pendidikan, sejarah pendidikan, ekonomi pendidikan, politik pendidikan dan sebagainya.

\section{B. Dasar Filosofis Pendidikan Islam}

Dasar filosofis pendidikan Islam merupakan kajian filosofis mengenai pendidikan Islam yang didasarkan al-Qur'an dan al-Hadits sebagai sumber primer, dan pendapat para ahli, khususnya para sahabat nabi SAW sebagai sumber sekunder. Dengan demikian secara singkat dapat dikatakan filsafat Islam adalah filsafat pendidikan yang berdasarkan ajaran Islam atau filsafat pendidikan yang dijiwai oleh ajaran Islam. 
Dasar-dasar pendidikan Islam secara prinsipiil diletakkan pada dasar-dasar ajaran Islam dan seluruh perangkat kebudayaannya. Dasardasar pembentukan dan pengembangan pendidikan Islam yang pertama dan utama tentu saja al-Qur'an dan sunnah. Al-Qur'an misalnya memberikan prinsip penghormatan kepada akal, bimbingan ilmiah, tidak menentang fitrah manusia dan memelihara kebutuhan sosial yang hal ini sangat penting bagi pendidikan. Dasar pendidikan Islam selanjutnya adalah nilai-nilai sosial kemasyarakatan yang tidak bertentangan dengan al-Qur'an dan al-Sunnah atas prinsip mendatangkan kemashlahatan dan menjauhkan kemudharatan bagi manusia. Kemudian warisan pemikiran para ulama dan cendekiawan muslim yang merupakan dasar penting dalam pendidikan Islam.

Di samping itu, di bagian lain Azyumardi Azra juga mengemukakan mengenai sumber dan dasar pendidikan Islam adalah alQur'an dan as-sunnah serta nilai-nilai, norma dan tradisi sosial yang memberi corak keislaman dan dapat mengikuti perkembangannya. Pendidikan Islam berpangkal dari ajaran Ilahiyah, maka tentu harus bersumber dari kebenaran dan kebesaran Ilahi. Bagi kita sumber kebenaran Ilahi telah diperkenalkan kepada manusia melalui para nabi berupa kitab suci. Dari empat kitab suci yang pernah diturunkan sebagai petunjuk umat manusia, maka sejak kehadiran Rasulullah SAW. di muka bumi ini satu yang harus ditegak kokohkan yakni al-Qur'an. Di samping itu ketetapanketetapan Rasul SAW juga merupakan sumber utama pendidikan Islam.

\section{Epistemologi Pendidikan Islam}

Dari beberapa literatur dapat disebutkan bahwa epistemology adalah teori pengetahuan, yaitu membahas tentang bagaimana cara mendapatkan pengetahuan dari objek yang ingin dipikirkan. D.W. Hamlyn 
mendefinisikan epistemologi sebagai cabang filsafat yang berurusan dengan hakikat dan lingkup pengetahuan dan pengandai pengandaiannya serta secara umum hal itu dapat diandalkannya sebagai penegasan bahwa orang memiliki pengetahuan. Selanjutnya, pengertian epistemologi yang lebih jelas, diungkapkan oleh Azyumardi Azra bahwa epistemologi sebagai ilmu yang membahas tentang keaslian, pengertian, struktur, metode, dan validitas ilmu pengetahuan. Dapat kita disimpulkan bahwa epistemologi merupakan salah satu komponen filsafat yang berhubungan dengan ilmu pengetahuan, khususnya berkenaan dengan cara, proses, dan prosedur bagaimana ilmu itu diperoleh.

Dalam pembahasan ini epistemologi pendidikan Islam lebih diarahkan pada metode atau pendekatan yang dapat dipakai untuk membangun ilmu pengetahuan Islam, dari pada komponen-komponen lainnya, sebab metode atau pendekatan tersebut paling dekat dengan upaya mengembangkan pendidikan Islam, baik secara konseptual maupun aplikatif. Epistemologi pendidikan Islam bisa berfungsi sebagai pengkritik, pemberi solusi, penemu, dan pengembang. Pendekatan epistemologi memerlukan cara atau metode tertentu, sebab ia menyajikan proses pengetahuan di hadapan siswa dibandingkan hasilnya.

Pendekatan epistemologi ini memberikan pemahaman dan keterampilan yang utuh dan tuntas. Seseorang yang mengetahui proses sesuatu kegiatan pasti mengetahui hasilnya. Sebaliknya, banyak yang mengetahui hasilnya tetapi tidak mengetahui prosesnya. Bisa dipastikan bahwa jika pendekatan epistemologi ini benar-benar diimplementasikan dalam proses belajar mengajar di lembaga pendidikan Islam, siswa dapat memiliki kemampuan memproses pengetahuan dari awal hingga wujud hasilnya.

Pendekatan epistemologi membuka kesadaran peserta didik untuk mendapatkan ilmu pengetahuan, bahkan dapat memberikan pemahaman dan keterampilan yang utuh. Di sisi lain epistemologi yang merupakan 
pendekatan yang berbasis proses akan melahirkan konsekuensikonsekuensi logis, sebagaimana berikut ini:

1. Menghilangkan paradigma dikotomi antara ilmu agama dan ilmu umum. Ilmu tidak bebas nilai tetapi bebas untuk dinilai; mengajarkan agama lewat bahasa ilmu pengetahuan dan tidak mengajarkan sisi tradisional saja, tetapi sisi rasional.

2. Mengubah pola pendidikan islam indoktrinasi menjadi pola partisipatif antara guru dan murid. Pola ini memberikan ruang bagi siswa untuk berpikir kritis, optimis, dinamis, inovatif, dan logis. Intinya pendekatan epistemologi ini menuntut guru dan siswa untuk sama-sama aktif dalam proses belajar mengajar.

3. Mengubah paradigma ideologis menjadi paradigma ilmiah yang berpijak pada wahyu Allah. Sebab paradigma ideologis ini karena otoritasnya dapat mengikat kebebasan tradisi ilmiah, kreatif, terbuka dan dinamis. Secara praktis, paradigma ideologis tidak memberikan ruang gerak pada penalaran atau pemikiran bebas yang bertanggung jawab secara argumentatif. Padahal, Al-Qur'an sangat memberikan keleluasaan bagi akal manusia untuk mengkaji, meneliti, mengobservasi, dan melakukan penemuan pada ayat kauniyah. Oleh karena itu agar epistemology pendidikan islam terwujud maka konsekuensinya harus berbijak pada wahyu Allah.

4. Guna menopang dan mendasari pendekatan epistemologi ini, perlu dilakukan rekonstruksi kurikulum yang masih sekuler dan bebas nilai spiritual ini menjadi kurikulum yang berbasis tauhid. Sebab pengetahuan yang bersumber dari hasil penelitian pada alam semesta (ayat kauniyah) dan ayat al-Qur'an atau naqliyah merupakan ilmu Allah. Ini berarti bahwa semua ilmu bersumber dari-Nya. Terkait dengan pengembangan kurikulum pendidikan islam, hal-hal yang sifatnya masih melangit, dogmatis dan transendental perlu diturunkan dan dikaitkan dengan dunia empiris dan lapangan. 
5. Epistemologi pendidikan islam diorientasikan pada hubungan yang harmonis antara akal dan wahyu. Maksudnya orientasi pendidikan Islam ditekankan pada pertumbuhan yang integrasi antara iman, ilmu, amal dan akhlak.

6. Konsekuensi yang lain adalah mengubah pendekatan dari pendekatan teoritis atau konseptual menjadi pendekatan konstektual atau aplikatif.

7. Adanya peningkatan profesionalisme tenaga pendidik dan penguasaan materi yang kompeherensif tentang materi ajar yang terintegrasi antara ilmu dan wahyu.

\section{Ontologi Pendidikan Islam}

Kata ontologi, berasal dari dua kata dasar yaitu Ontos dan Logos. Ontos yang berarti Ada dan Logos yang berarti Ilmu. Sehingga secara global istilah ontologi bisa diartikan sebagai suatu ilmu yang mengkaji tentang hakikat dari segala sesuatu Yang-Ada. Hakikat dalam kajian ontologi adalah keadaan sebenarnya dari sesuatu, bukan keadaan sementara yang selalu berubah-ubah.

Ontologi pendidikan Islam adalah menyelami hakikat dari pendidikan Islam, kenyataan dalam pendidikan Islam dengan segala pola organisasi yang melingkupinya, meliputi hakikat pendidikan Islam dan ilmu pendidikan Islam, hakikat tujuan pendidikan Islam, hakikat manusia Jumhur, "Karakteristik Pendidikan Islam sebagai subjek pendidikan yang ditekankan kepada pendidik dan peserta didik, dan hakikat kurikulum pendidikan Islam.

\section{Konsep Pendidikan Dalam Islam}

Heri jauhari menyebutkan bahwasanya pendidikan adalah segala usaha yang dilakukan untuk mendidik manusia sehingga dapat tumbuh dan berkembang serta serta memiliki potensi atau kemampuan 
sebagaimana mestinya. Menurut Hasan al-Banna -sebagaimana dikutip A. Susanto- konsep pendidikan islam meliputi tiga sisi, yaitu pengembangan potensi jasmani, akal dan hati sebagai tiga unsur pokok yang dimiliki manusia dan sekaligus sebagai pewarisan kebudayaan Islam.

Hamka berpendapat pendidikan terbagi menjadi dua. Pertama, pendidikan jasmani, yaitu pendidikan untuk pertumbuhan dan kesempurnaan jasmani serta kekuatan jiwa dan akal. Kedua, pendidikan ruhani, yaitu pendidikan untuk kesempurnaan fitrah manusia dengan ilmu pengetahuan dan pengalaman yang didasarkan agama, kedua unsur tersebut memiliki kecendrungan untuk berkembang. Hal ini sebagaimana disadur oleh A.Susanto dalam Pemikiran pendidikan Islam.

\section{Tujuan Pendidikan dalam Islam}

Tujuan adalah suatu yang diharapkan tercapai setelah sesuatu usaha atau kegiatan selesai; artinya tujuan merupakan kehendak seseorang untuk mendapatkan dan memiliki, serta memanfaatkannya bagi kebutuhan dirinya sendiri atau untuk orang lain. Menurut Hasan Langgulung sebagaimana disebutkan Abuddin Nata bahwa tujuan pendidikan agama harus mampu mengakomodasikan tiga fungsi utama dari agama, yaitu fungsi spiritual yang berkaitan dengan akidah dan iman, fungsi psikologis yang berkaitan dengan tingkah laku individual termasuk akhlak, dan fungsi social yang berkaitan dengan aturan-aturan yang menghubungkan manusia dengan manusia lain serta masyarakat dengan masyarakat lain sehingga terjalin hubungan yang harmonis dan seimbang.

\section{Hakikat Manusia dalam Pendidikan Islam}

Manusia dalam pandangan Al-Qur' an adalah makhluk unik (luar biasa) lantaran kedudukannya sebagai khalifah. Manusia mempunyai fitrah yang baik, kemampuan berkehendak (free will), badan raga, ruh dan akal. Dengan 
demikian, pendidikan harus mengembangkan atribut-atribut manusia tersebut. Demikian pula pendidikan Islam bertujuan membentuk manusia yang beriman yang menyadari dan memperhatikan komponen-komponen fitrahnya, tanpa mengorbankan salah satu demi pengembangan yang lain.

Inti dari konsep pendidikan menurut Al-Qur'an adalah proses pengembangan dan pembetukan manusia yang selalu berlandaskan tauhid/mengesakan Allah, beribadah dan membesarkan nama-Nya. Karena Allah tiada menciptakan manusia kecuali beribadah untuk menyembah-Nya. (Q.S. adz-Dzaariyaat: 56).

\section{Kurikulum dalam Pendidikan Islam}

Kurikulum dalam pendidikan Islam, yaitu kata manhaj, yang bermakna jalan yang terang, atau jalan terang yang dilalui oleh manusia pada bidang kehidupannya. Jadi, kurikulum yang dimaksud adalah jalan terang yang dilalui oleh pendidik atau guru latih dengan orang yang dididik atau dilatihnya untuk mengembangkan pengetahuan, ketrampilan dan sikap mereka.

Keberadaan kurikulum dalam pendidikan Islam sebagai alat untuk mendidik generasi muda dengan baik dan menolong mereka untuk membuka dan mengembangkan kesediaan-kesediaan, bakat-bakat, kekuatan-kekuatan, dan keterampilan mereka yang bermacam-macam dan menyiapkan mereka dengan baik untuk menjalankan hak-hak dan kewajiban, memikul tanggung jawab terhadap diri, keluarga, masyarakat, bangsanya dan turut serta secara aktif untuk kemajuan masyarakat dan bangsanya.

Alat pendidikan yang di maksudkan penulis adalah media untuk terlaksananya proses pendidikan, maka alat di sini mencakup apa saja yang dapat digunakan termasuk di dalamnya metode pendidikan menurut al- 
Qur'an. Sehingga metode dan alat pendidikan dalam masyarakat adalah cara dan segala apa saja yang dapat digunakan untuk menuntun dan membimbing setiap individu masyarakat dalam usaha membentuk kepribadian muslim yang diridhai Allah. Oleh karena itu, alat dan metode pendidikan dalam masyarakat haruslah searah dengan Al-Qur'an dan as-Sunnah.

Kurikulum mempunyai peran penting dalam upaya untuk mencapai tujuan pendidikan. Apalagi ini tujuan pendidikan Islam yang begitu kompleks, seorang anak didik tidak hanya memiliki kemampuan secara afektif, kognitif maupun psikomotor, tetapi dalam dirinya harus tertanam sikap dan pribadi yang berakhlakul karimah yang selalu berlandaskan tauhid/ mengesakan Allah, beribadah kepada-Nya.

\section{E. Aksiologi Pendidikan Islam}

Aksiologis membahas tentang hakikat nilai, yang didalamnya meliputi baik dan buruk (good and bad), benar dan salah (right and wrong), serta tentang cara dan tujuan (means and ends). Cara memandangnya dari sudut baik dan tidak baik, etika merupakan filsafat tentang perilaku manusia. pendidikan Islam diorientasikan pada upaya menciptakan suatu kepribadian yang mantap dan dinamis, mandiri dan kreatif. Tidak hanya pada siswa melainkan pada seluruh komponen yang terlibat dalam penyelenggaraan pendidikan Islam.

Terwujudnya kondisi mental-moral dan spiritual religius menjadi target arah pengembangan sistem pendidikan Islam. Oleh sebab itu, berdasarkan pada pendekatan etik moral pendidikan Islam harus berbentuk proses pengarahan perkembangan kehidupan dan keberagamaan pada peserta didik ke arah idealitas kehidupan Islami, dengan tetap memperhatikan dan memperlakukan peserta didik sesuai dengan potensi dasar yang dimiliki serta latar belakang sosio budaya masing-masing. 
Selain konteks etika profetik, aksiologis dalam pendidikan Islam meliputi estetika yang merupakan nilai-nilai yang berkaitan dengan kreasi yang berhubungan dengan seni. Dengan seni itulah, nantinya bisa dijadikan sebagai media dan alat kesenangan, sebagai ekspresi yang sebenarnya tentang pengalaman.

Namun, lebih jauh dari itu, maka dalam dunia pendidikan hendaklah nilai estetika menjadi patokan penting dalam proses pengembangan pendidikan yakni dengan menggunakan pendekatan estetis-moral, di mana setiap persoalan pendidikan Islam dilihat dari perspektif yang mengikutsertakan kepentingan masing-masing pihak, baik itu siswa, guru, pemerintah, pendidik serta masyarakat luas. Ini berarti pendidikan Islam diorientasikan pada upaya menciptakan suatu kepribadian yang kreatif, berseni (sesuai dengan Islam) sehingga pendidikan Islam tetap memiliki daya tarik dan kajian yang senantiasa berkesinambungan serta relevan hingga akhir zaman.

Ada beberapa nilai etika profetik dalam rangka pengembangan dan penerapan Ilmu Pendidikan Islam, yaitu:

1. Nilai ibadah, yakni bagi praktisi dan pemerhati pendidikan Islam, dalam segala proses dan berpikirnya senantiasa tercatat sebagai ibadah (QS. Ali Imran: 191).

2. Nilai ihsan, yakni penyelenggaraan pendidikan Islam hendaknya dikembangkan atas dasar berbuat baik terhadap sesama. (QS. alQashash: 77).

3. Nilai masa depan, pendidikan Islam hendaknya ditujukan untuk mengantisipasi masa depan yang lebih baik, karena mendidik berarti menyiapkan generasi yang hidup dengan tantangan yang jauh berbeda dengan periode sebelumnya, yakni menyiapkan sumber daya manusia yang cakap, terampil dan profesional. (QS. al-Hasyr: 18).

4. Nilai kerahmatan, yakni ilmu pendidikan Islam hendaknya ditujukan bagi kepentingan dan kemaslahatan seluruh umat manusia dan alam semesta, sebagaimana termaktub dalam QS.alAnbiya': 107. 
5. Nilai dakwah, yakni penerapan dan pengembangan ilmu pendidikan Islam merupakan wujud penyebaran syiar Islam.

6. Maka kemudian, jika landasan ini senantiasa menjadi pegangan hidup dalam lingkup pendidikan Islam, maka unsur aksiologis pendidikan Islam tetap abadi dan sesuai dengan harapan dan kebutuhan masyarakat.

\section{DAFTAR BACAAN}

Abas, E. (2019). The Effect of Madrasah Principal's Leadership and Teachers' Work Motivation on Learning Effectiveness in Bandar Lampung. Jurnal Ilmiah Peuradeun, 7(2), 305-314. doi:10.26811/peuradeun.v7i2.271

Abbas, S., Tabrani ZA, \& Murziqin, R. (2016). Responses of the Criminal Justice System. In International Statistics on Crime and Justice (pp. 87109). Helsinki: HEUNI Publication.

Abdullah, A., \& Tabrani ZA. (2018). Orientation of Education in Shaping the Intellectual Intelligence of Children. Advanced Science Letters, 24(11), 8200-8204. https:/ / doi.org/10.1166/asl.2018.12523

Abubakar, A., Srimulyani, E., \& Anwar, A. (2019). Identification of Some Distinctive Values of Acehnese Malee (Shyness) for Character Education. Jurnal Ilmiah Peuradeun, 7(1), 125-140. doi:10.26811/peuradeun.v7i1.224

Acosta, M. (2016). Paradigm Shift in Open Education and E-Learning Resources as Teaching and Learning in Philippines. Jurnal Ilmiah Peuradeun, 4(2), 161-172. doi:10.26811/peuradeun.v4i2.94

Anim, A., Prasetyo, Y., \& Rahmadani, E. (2019). Experimentation of Problem Posing Learning Model Assisted of Autograph Software to Students' Mathematical Communication Ability in Terms of Student's Gender. Jurnal Ilmiah Peuradeun, 7(2), 331-342. doi:10.26811/peuradeun.v7i2.301

AR, M., Usman, N., Tabrani ZA, \& Syahril. (2018). Inclusive Education Management in State Primary Schools in Banda Aceh. Advanced Science Letters, 24(11),

8313-8317. https://doi.org/10.1166/asl.2018.12549

Bustamam-Ahmad, K. (2019). The Religious Imagination in Literary 
Network and Muslim Contestation in Nusantara. Jurnal Ilmiah Peuradeun, 7(2), 217-244. doi:10.26811/peuradeun.v7i2.344

Dewi, N., \& Atun, S. (2019). The Effect of Science Technology Society (STS) Learning On Students' Science Process Skills. Jurnal Ilmiah Peuradeun, 7(1), 113-124. doi:10.26811/peuradeun.v7i1.288

Fitriani, N., \& Sabarniati, S. (2019). A Feedback Investigation of Comparing Teacher and Students' Preferences on Writing Conference in a Novice EFL Writing Class. Jurnal Ilmiah Peuradeun, 7(2), 315-330. doi:10.26811/peuradeun.v7i2.304

Haji Musa, N., \& Mohd Yusoff, M. (2019). Professional Values Influence on the Teachers' Quality of Islamic Secondary School. Jurnal Ilmiah Peuradeun, 7(2), 295-304. doi:10.26811/peuradeun.v7i2.415

Hughes, K., \& Batten, L. (2016). The Development of Social and Moral Responsibility in Terms of Respect for the Rights of Others. Jurnal Ilmiah Peuradeun, 4(2), 147-160. doi:10.26811/peuradeun.v4i2.93

Idris, S., \& Tabrani ZA. (2017). Realitas Konsep Pendidikan Humanisme dalam Konteks Pendidikan Islam. JURNAL EDUKASI: Jurnal Bimbingan Konseling, 3(1), 96-113. https://doi.org/10.22373/je.v3i1.1420

Idris, S., Tabrani ZA, \& Sulaiman, F. (2018). Critical Education Paradigm in the Perspective of Islamic Education. Advanced Science Letters, 24(11), 8226-8230. https://doi.org/10.1166/asl.2018.12529

Kaylene, P., \& Rosone, T. (2016). Multicultural Perspective on the Motivation of Students in Teaching Physical Education. Jurnal Ilmiah Peuradeun, 4(1), 115-126. doi:10.26811/peuradeun.v4i1.90

Lewis, M., \& Ponzio, V. (2016). Character Education as the Primary Purpose of Schooling for the Future. Jurnal Ilmiah Peuradeun, 4(2), 137-146. doi:10.26811/peuradeun.v4i2.92

Lvina, E. (2015). The Role of Cross-Cultural Communication Competence: Effective Transformational Leadership Across Cultures. Jurnal Ilmiah Peuradeun, 3(1), 1-18.

Meraj, M. (2016). Islamic Approach to the Environment and the Role's in the Environment Protected. Jurnal Ilmiah Peuradeun, 4(1), 1-14. doi:10.26811/peuradeun.v4i1.81

Mohd. Yusuff, M., Haji Othman, M., Suhid, A., \& Khalid, R. (2019). The Practice of Noble Values among Primary School Students in 
Malaysia. Jurnal Ilmiah Peuradeun, 7(1), 163-180. doi:10.26811/peuradeun.v7i1.385

Murziqin, R., \& Tabrani ZA. (2016). The Importance of Local Parties and Incumbency to the Electoral in Aceh. Journal of Islamic Law and Culture, 10(2), 123-144.

Musradinur, \& Tabrani ZA. (2015). Paradigma Pendidikan Islam Pluralis Sebagai Solusi Integrasi Bangsa (Suatu Analisis Wacana Pendidikan Pluralisme Indonesia). 1st Annual International Seminar on Education 2015, 77-86. Banda Aceh: FTK Ar-Raniry Press.

Muttaqin, F. (2015). Early Feminist Consciousness and Idea Among Muslim Women in 1920s Indonesia. Jurnal Ilmiah Peuradeun, 3(1), 19-38.

Nasution, W. (2018). The Effectiveness of Teachers' Performance of Islamic Junior High School in Islamic Boarding School Langkat District, Indonesia. Jurnal Ilmiah Peuradeun, 6(2), 325-338. doi:10.26811/peuradeun.v6i2.285

Nufiar, N., \& Idris, S. (2016). Teacher Competence Test of Islamic Primary Teachers Education in State Islamic Primary Schools (MIN) of Pidie Regency. Jurnal Ilmiah Peuradeun, 4(3), 309-320. doi:10.26811/peuradeun.v4i3.105

Patimah, S., \& Tabrani ZA. (2018). Counting Methodology on Educational Return Investment. Advanced Science Letters, 24(10), 7087-7089. https://doi.org/10.1166/asl.2018.12414

Salami, S. (2015). Implementing Neuro Linguistic Programming (NLP) in Changing Students' Behavior: Research Done at Islamic Universities in Aceh. Jurnal Ilmiah Peuradeun, 3(2), 235-256.

Siswanto, R., Sugiono, S., \& Prasojo, L. (2018). The Development of Management Model Program of Vocational School Teacher Partnership with Business World and Industry Word (DUDI). Jurnal Ilmiah Peuradeun, 6(3), 365-384. doi:10.26811/peuradeun.v6i3.322

Syahrir, S. (2018). Islamic Education with National Insight Viewed from Islamic Perspective. Jurnal Ilmiah Peuradeun, 6(1), 121-140. doi:10.26811/peuradeun.v6i1.192

Tabrani ZA \& Murziqin, R. (2015). Political Education in Maturation Democracy in Indonesia. British Journal of Political Science, 45 (1), 215-226

Tabrani ZA, \& Masbur. (2016). Islamic Perspectives on the Existence of Soul 
and Its Influence in Human Learning (A Philosophical Analysis of the Classical and Modern Learning Theories). JURNAL EDUKASI: Jurnal Bimbingan Konseling, 1(2), 99-112. Retrieved from http://jurnal.ar-raniry.ac.id/index.php/cobaBK/article/view/600

Tabrani ZA. (2009). Ilmu Pendidikan Islam (antara Tradisional dan Modern). Kuala Lumpur: Al-Jenderami Press.

Tabrani ZA. (2011a). Dynamics of Political System of Education Indonesia. International Journal of Democracy, 17(2), 99-113.

Tabrani ZA. (2011b). Nalar Agama dan Negara dalam Perspektif Pendidikan Islam. (Suatu Telaah Sosio-Politik Pendidikan Indonesia). Millah Jurnal Studi Agama, 10(2), 395-410.

Tabrani ZA. (2012). Future Life of Islamic Education in Indonesia. International Journal of Democracy, 18(2), 271-284.

Tabrani ZA. (2013a). Modernisasi Pengembangan Pendidikan Islam (Suatu Telaah Epistemologi Pendidikan). Serambi Tarbawi, 1(1), 65-84.

Tabrani ZA. (2013b). Pengantar Metodologi Studi Islam. Banda Aceh: SCAD Independent.

Tabrani ZA. (2013c). Urgensi Pendidikan Islam dalam Pemberdayaan Masyarakat. Jurnal Sintesa, 13(1), 91-106.

Tabrani ZA. (2013d). Kebijakan Pemerintah dalam Pengelolaan Satuan Pendidikan Keagamaan Islam (Tantangan Terhadap Implementasi Manajemen Berbasis Sekolah). Serambi Tarbawi, 1(2), 65-84.

Tabrani ZA. (2014). Dasar-Dasar Metodologi Penelitian Kualitatif. Yogyakarta: Darussalam Publishing.

Tabrani ZA. (2015a). Arah Baru Metodologi Studi Islam. Yogyakarta: Penerbit Ombak.

Tabrani ZA. (2015b). Persuit Epistemology of Islamic Studies (Buku 2 Arah Baru Metodologi Studi Islam). Yogyakarta: Penerbit Ombak.

Tabrani ZA. (2015c). Keterkaitan Antara Ilmu Pengetahuan dan Filsafat (Studi Analisis atas QS. Al-An`am Ayat 125). Jurnal Sintesa, 14(2), 114.

Tabrani ZA. (2016). Perubahan Ideologi Keislaman Turki (Analisis GeoKultur Islam dan Politik Pada Kerajaan Turki Usmani). JURNAL EDUKASI: Jurnal Bimbingan Konseling, 2(2), 130-146. https://doi.org/10.22373/je.v2i2.812 
Tabrani ZA. (2017). Menggugat Logika Nalar Rasionalisme Aristoteles. Yogyakarta: Mizan.

Tan, C. (2015). Educative Tradition and Islamic School in Indonesia. Jurnal Ilmiah Peuradeun, 3(3), 417-430.

Usman, N., AR, M., \& Marzuki, M. (2016). The Influence of Leadership in Improving Personnel Performance at Traditional Islamic Boarding School (Dayah). Jurnal Ilmiah Peuradeun, 4(2), 205-216. doi:10.26811/peuradeun.v4i2.98

Usman, N., AR, M., Murziqin, R., \& Tabrani ZA. (2018). The Principal's Managerial Competence in Improving School Performance in Pidie Jaya Regency. Advanced Science Letters, 24(11), 8297-8300. https://doi.org/10.1166/asl.2018.12545

Usman, N., AR, M., Syahril, Irani, U., \& Tabrani ZA. (2019). The implementation of learning management at the institution of modern dayah in aceh besar district. Journal of Physics: Conference Series, 1175(1), $012157 . \quad$ https://doi.org/10.1088/17426596/1175/1/012157

Vohra, S. (2015). The Practice of Dowry in the Perspective of Hinduism In India. Jurnal Ilmiah Peuradeun, 3(3), 363-370.

Walidin, W., Idris, S., \& Tabrani ZA. (2015). Metodologi Penelitian Kualitatif $\mathcal{E}$ Grounded Theory. Banda Aceh: FTK Ar-Raniry Press.

Warisno, A., \& Tabrani ZA. (2018). The Local Wisdom and Purpose of Tahlilan Tradition. Advanced Science Letters, 24(10), 7082-7086. https://doi.org/10.1166/asl.2018.12413

Wekke, I., Arif, B., Zubair, A., \& Wardi, M. (2019). The Role of Muhammadiyah Institution Towards Muslim Minority in West Papua. Jurnal Ilmiah Peuradeun, 7(1), 21-42. doi:10.26811/peuradeun.v7i1.311

Zanabazar, A., \& Battuya, B. (2019). Current Status of Social Responsibility for Mongolian Mining Companies. Jurnal Ilmiah Peuradeun, 7(2), 245256. doi:10.26811/peuradeun.v7i2.409 